\title{
Response of inoculation technique to seed and seedling infection by M. phaseolina in sorghum
}

\author{
R. Sukanya, S. K. Jayalakshmi
}

Department of plant pathology, University of Agricultural Sciences, Raichur, Karnataka, India

\begin{abstract}
Sorghum is a major cereal of the world and is a staple food for millions of the poorest and most food insecure people. The yield and quality of sorghum is affected by a wide array diseases among them charcoal rot of sorghum caused by Macrophomina phaseolina (Tassi) Goid. is causing more yield loss in rabi sorghum growing areas compared to kharif. Different inoculation techniques were followed to know effective method for infecting the seeds and seedlings by the pathogen among method $C$, that is seed soaking in spore suspension method recorded maximum pre and post emergence mortality of seeds are 43 and 27 per cent respectively compared to other methods.
\end{abstract}

Keywords- Sorghum, Charcoal rot and Macrophomina phaseolina Seedling mortality.

\section{INTRODUCTION}

Sorghum (Sorghum bicolor (L.) Moench) a major cereal of the world after wheat, rice, maize and barley, is a staple food for millions of the poorest and most food insecure people in the Semi-Arid Tropics (SAT) of Africa and Asia. Sorghum commonly known as durra, jowari or milo, parts of the world grow sorghum both in rainy and post rainy seasons in India. The yield and quality of sorghum is affected by a wide array of biotic (pests and diseases) and abiotic (drought and problematic soils) stresses. Among the biotic factors of many diseases of sorghum, charcoal rot of sorghum caused by Macrophomina phaseolina (Tassi) Goid. is causing more yield loss in rabi sorghum growing areas compared to kharif. It is mainly soil inhabiting fungus is an important root and stalk pathogen that incites the disease by producing microsclerotia/pycnidia (Farr et al., 1995; Pun et al., 1998). The pathogen causes disease in over 500 plant species from 75 families with heterogeneous host specificity i.e. the ability to infect monocots as well as dicots and can exhibit non-uniform distribution in the soil (Mayek-Perez et al., 2001 and Su et al., 2001).

\section{MATERIAL AND METHODS}

To check the seed and seedling mortality due to sorghum M. phaseolina different techniques used to infect seeds was followed in laboratory condition.

A) Seed roll technique: Sorghum seeds (20) rolled on 7 days old culture of $M$. phaseolina on the culture Petri plate, and Petri plate rotated in both clockwise and anticlockwise so that seed surface get covered by sclerotia. The pathogen coated seeds were kept for germination on blotter paper and folded were then kept in an incubator at $30{ }^{\circ} \mathrm{C}$ for ten days. The blotters were moistened with sterile water every day. At the end of the incubation period, the per cent seed and seedling mortality were recorded.

B) Sorghum seedling dip technique: Twenty sorghum seeds were kept for germination for four days then the seedling roots were dipped for $2 \mathrm{~min}$ in $M$. phaseolina spore suspension of $10^{5}$ spore per $\mathrm{ml}$ and these seedlings kept for germination. At the end of the incubation period, the per cent seed and seedling mortality observation were recorded.

C) Seed soaking technique: This method was followed as paper towel technique. The fungus was cultured on Potato Dextrose Broth (PDB). Twenty $\mathrm{ml}$ of PDB was poured into $100 \mathrm{ml}$ conical flasks and sterilized. The flasks were then inoculated and incubated for ten days. The mycelial mat from the flask was removed and macerated in a waring blender along with distilled water for a minute. The inoculum was later collected in a beaker. In the mean time, 20 sorghum seeds of M-35-1 were immersed completely in the inoculum for 12 hours. These seeds were then placed side by side on a blotter paper (45 cm x $25 \mathrm{~cm}$ with one fold) and was folded. The folded blotter papers were then placed in trays, and kept in an incubator at $30^{\circ} \mathrm{C}$ for ten days. The blotters were moistened with sterile water every day. At the end of the incubation period, the per cent seedlings infection observations were recorded. 


\section{RESULT AND DISCUSSION}

Different inoculation techniques were followed to know effective method for infecting the seeds and seedlings by the pathogen as given in materials and methods and in these methods maximum seed and seedling mortality was observed. In method $\mathrm{C}$, that is seed soaking in spore suspension method recorded maximum pre and post emergence mortality of seeds are 43 and 27 per cent respectively, whereas in seedling dip technique pre and post emergence mortality was recorded 0.00 and 45.35 per cent respectively and in seed rolling method least pre and post emergence mortality was recorded as 15.00 and 20.45 per cent respectively (Table 1). Results revealed that maximum mortality of seedling was observed in seed soaking methods. These methods can be further used to carry out other experiments. The results are in accordance with the findings of Jayalakshmi (2009) who conducted inoculation technique on Fusarium oxysporum fsp ciceri and $M$. phaseolina infection to chickpea and also Galli et al. (2005) studied that to identify the optimal period for infection of maize seeds on agar colonized by Fusarium graminearum, when incubated for $4,8,16$ and $32 \mathrm{~h}$, and to evaluate the effect of the fungus on the germination and vigor of seeds with different infection levels.

\section{REFERENCES}

[1] Farr, D. F., Bills, G. F., Chamuris, G. P. and Rossman, A. Y., 1995, Fungi on plants and plant products in the United States, 2nd ed. St Paul (MN): APS Press. pp. 35.

[2] Galli, J. A., Fessel, S. A. and Panizzi, R. C., 2005, Effect of Fusarium graminearum and infection index on germination and vigor of maize seeds. Fitopatolo. Brasileira, 30: 470-474.

[3] Jayalaxmi, S. K., 2009, Studies on the management of wilt complex in chickpea by native isolate, Trichoderma species. Ph. D. Thesis, Anamalai University.

[4] Mayek-Perez, N., Lopez-Castaneda, C., GonzalezChavira, M., Garch-Espinosa, R., Acosta-Gallegos, J., De la Vega, O. M. and Simpson, J., 2001. Variability of Mexican isolates of Macrophomina phaseolina based on pathogenesis and AFLP genotype. Physiol Mol. Plant Pathol., 59: 257-264.

[5] Pun, K. B., Sabitha, D. and Valluvaparidasan, V., 1998, Studies on seed-borne nature of Macrophomina phaseolina in okra. Plant Dis. Res., 13: 249-290.

[6] Su, G., Suh, S. O., Schneider, R. W. and Russin, J. S., 2001, Host specialization in the charcoal rot fungus Macrophomina phaseolina. Phytopathol., 91: 120-126.

Table.1: Response of inoculation technique to seed and seedling infection by M. phaseolina

\begin{tabular}{|c|c|c|}
\hline Treatment & Pre emergence mortality $(\boldsymbol{\%})$ & Post emergence mortality (\%) \\
\hline Seed rolling method (A) & $15.00(22.79)$ & $20.45(26.89)$ \\
\hline Seedling dip method (B) & $00.00(00.00)$ & $45.35(42.23)$ \\
\hline Seed soaking method (C) & $43.00(40.97)$ & $27.00(31.30)$ \\
\hline Control & $00.00(00.00)$ & $00.00(00.00)$ \\
\hline S.Em \pm & 0.500 & 0.306 \\
\hline CD @ 1\% & 2.065 & 1.265 \\
\hline
\end{tabular}

